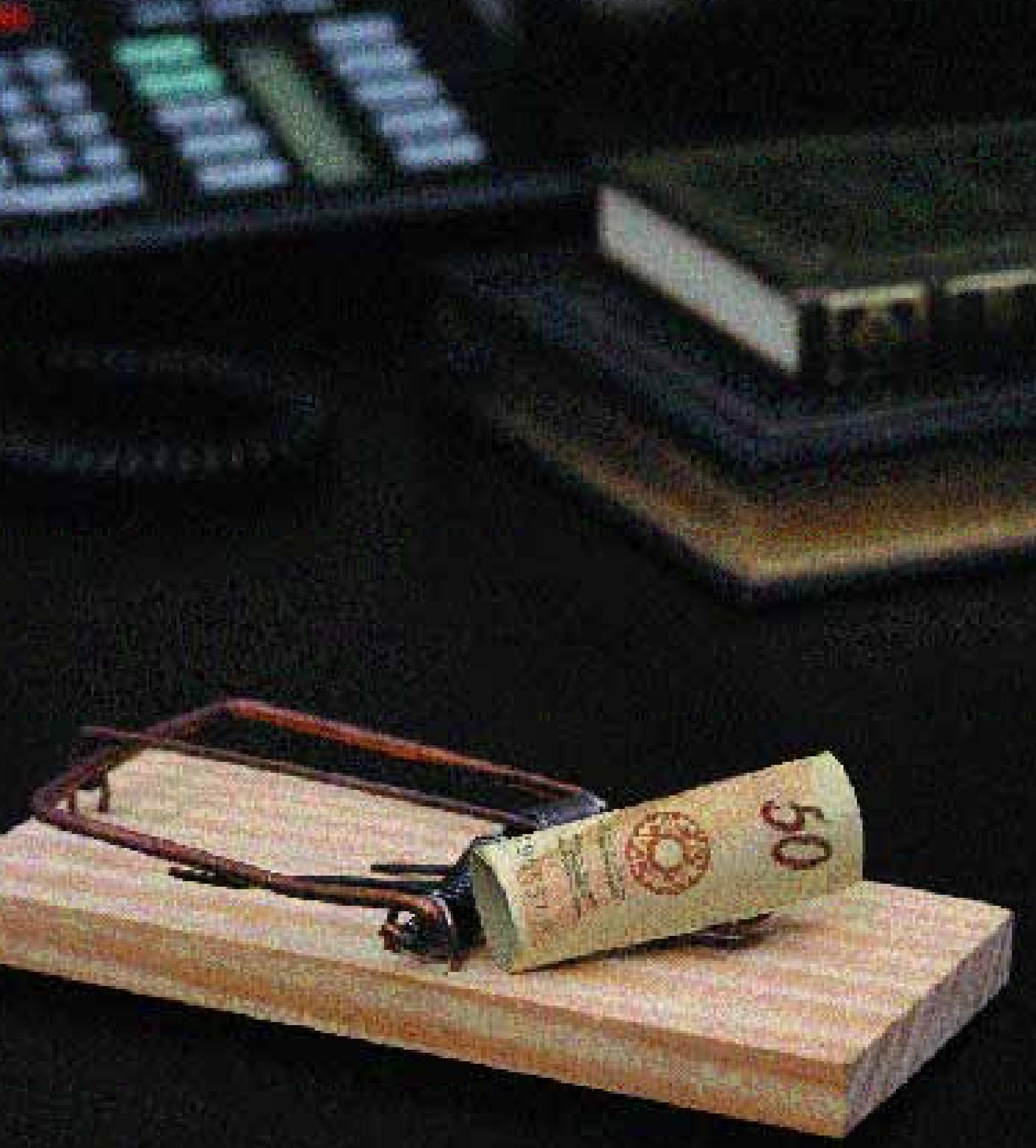




\section{Cleptocracia brasileira}

1 liberalização democrática brasileira não coincidiu com a eliminação da corrupção crônica. A proliferação de escândalos demonstra que a sociedade não é ainda capaz de controlar o fenômeno. Sob um regime democrático, a corrupção é inaceitável, porque os cidadãos elegem seus pares para representá-los, e não para trabalhar contra eles. Tornar a corrupção objeto de análise econômica pode contribuir para a compreensão e o combate ao fenômeno.

por Marcos Fernandes Gonçalves da Silva FGV-EAESP

No Brasil, existe uma dispendiosa máquina institucional para conter a corrupção, mas esta continua disseminada e aparentemente fora de controle. A impunidade é a regra, não a exceção. O sistema de controle compõe-se de seis unidades independentes: a Secretaria Federal de Controle, o Sistema Integrado de Administração Financeira - Siafi -, a Advocacia Geral da União, o Tribunal de Contas da
União (TCU), o Ministério Público e a Polícia Federal. A Secretaria Federal de Controle é composta por 23 secretarias internas que agem em cada ministério e estão representadas em todos os estados da União. O sistema emprega cerca de 3 mil pessoas, entre técnicos e auditores. Essas agências têm por objetivo monitorar e supervisionar o uso do Orçamento Federal. 
A Siafi, por sua vez, é um sistema on line de informação de dados que tem por objetivo fornecer dados referentes ao uso do orçamento. Os clientes do sistema são políticos e a própria Secretaria Federal de Controle (desde 1996, todos os cidadãos têm direito de acesso aos arquivos).

A Advocacia Geral da União emprega cerca de 200 funcionários públicos para investigar suspeitas de corrupção e defender a Federação de operações corruptas.

O TCU desempenha uma função de supervisão e tem poderes para processar e punir quem se envolver com essas práticas (mesmo que seja o Presidente). Emprega aproximadamente 2 mil funcionários.

A função do Ministério Público é a de investigar e denunciar à Justiça casos internos de corrupção do governo. Emprega cerca de 3 mil funcionários - entre os quais, mais de 300 promotores.

Finalmente, a Polícia Federal, representada pela Receita Federal, é encarregada de investigar casos de corrupção e de evasão fiscal. Tem mais de 200 funcionários, incluindo investigadores.

Um breve exame do Orçamento Federal revela que, em 1995, os contribuintes brasileiros gastaram US\$ 330 milhões no pagamento dos funcionários desse grande sistema de controle. Adicionalmente, há unidades que desempenham funções semelhantes nos estados e municípios. Conseqüentemente, não se pode dizer que haja falta de unidades de controle - salvo no caso da Receita Federal. Com um mínimo de esforço e competência, essa estrutura anticorrupção poderia funcionar.

\section{O estabelecimento da democracia e}

\section{de maiores poderes ao Congresso não}

\section{trouxe qualquer aperfeiçoamento ao}

\section{sistema de controle da corrupção.}

O estabelecimento da democracia e de maiores poderes ao Congresso não trouxe qualquer aperfeiçoamento ao sistema de controle. Tal fato conduz a uma questão importante: se há um dispendioso sistema de controle e se é pos- sível investigar o comportamento dos agentes públicos, por que é tão difícil controlar a corrupção? Acreditamos que qualquer especulação a respeito de uma possível resposta a essa pergunta dependa do exame concreto dos fatos e da análise da economia política da corrupção na história contemporânea do Brasil.

Falta de controle ou tolerância? Dois dos mais conhecidos casos de corrupção na história recente do país têm algo importante em comum. Eles não foram revelados por investigações realizadas pelo Congresso ou pelo sistema federal de controle. Pelo contrário, surgiram acidentalmente. O escândalo Collor foi resultado de intrigas em família, e a corrupção orçamentária emergiu em meio a uma investigação de homicídio que não estava diretamente relacionada ao caso. Examinemos algo a respeito do segundo caso, por ser ele um bom exemplo e demonstrar o drama absurdo do mau uso de dinheiro público.

De fato, o caso assemelha-se a um conto policial. O economista José Carlos Alves dos Santos, um alto funcionário do Senado, estava sendo investigado pelo homicídio de sua esposa, seqüestrada e morta sob circunstâncias misteriosas. A polícia o considerava como principal suspeito. Em uma diligência em sua casa, os investigadores encontraram milhares de dólares, parte dos quais era falsificada. Perguntado sobre a origem do dinheiro, o funcionário afirmou que vinha de atividades ilegais ligadas ao processo orçamentário federal.

O economista era um profissional brilhante. Sua carreira pública começara na qualidade de assistente técnico do Senado, em 1965. Em 1985, tornara-se um assistente orçamentário e, em 1988, era o principal funcionário do Legislativo encarregado do processo orçamentário no Congresso. Mais tarde, ocupou o posto de assessor técnico da Comissão do Orçamento. Em 1991, foi indicado para o Departamento do Orçamento da União (DOU), uma unidade do Executivo, retornando ao Legislativo em 1992.

Esse perito nos labirintos da legislação orçamentária era um dos elementos mais importantes de um esquema de corrupção que abalou mais uma vez a credibilidade do Congresso. Na qualidade de profissional especialista em temas orçamentários, o economista articu- 


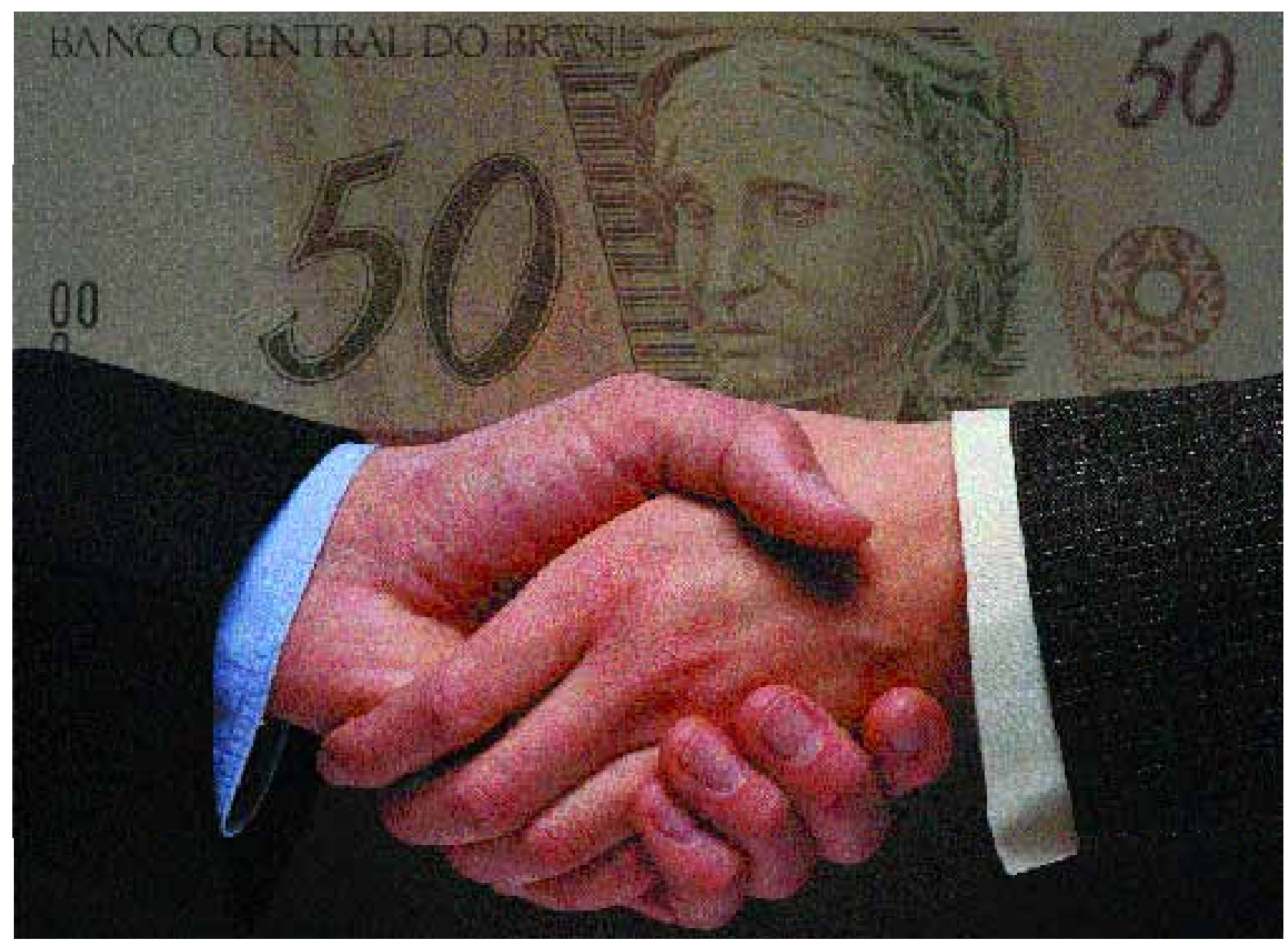

lara um grande esquema de corrupção que envolvia políticos e agentes privados.

$O$ escândalo foi estruturado em dois esquemas paralelos. O primeiro era conhecido como "esquema das empreiteiras" e o segundo como "esquema de transferências sociais". Ambos deram-se no Congresso, mas foram organizados na máquina política do Poder Executivo. O elemento comum aos dois esquemas era a Comissão do Orçamento.

Muitos grupos políticos tinham poder de influência antes do processo legal orçamentário do Congresso. Eles usavam essa influência para desenvolver as propostas de alocação das unidades orçamentárias (os Ministérios) e, assim, satisfazer seus interesses. Desse ponto em diante, utilizavam tal influência sobre a Comissão do Orçamento para sancionar a alocação de receitas e desembolsos.

Os políticos envolvidos no caso ficaram conhecidos como os "sete anões". A etapa mais importante da operação era o processo orçamentário do Congresso. Um pequeno grupo de congressistas - os "sete anões" - havia tomado o controle da Comissão do Orçamento para garantir os interesses dos beneficiários e lobistas por eles representados durante o processo orçamentário.

O principal indício de corrupção era o alto nível de aprovação das emendas propostas pelos membros da Comissão. Mas havia outros indícios: (1) os distritos dos congressistas eram favorecidos; (2) algumas empreiteiras beneficiavam-se desproporcionalmente dos desembolsos aprovados; e (3) o cumprimento das aprovações de execução de recursos, apesar do forte controle fiscal. Esses fatos revelaram o nível do clientelismo e das relações patrimoniais existentes no Congresso.

O primeiro esquema estava ligado a empreiteiras que faziam uma espécie de rodízio no vencimento de concor- 
rências públicas. O cartel promovia a escolha das vencedoras, sem qualquer controle público. Outro meio de ação utilizado era o dos negócios com governos de estados e municípios. Uma vez aceita a transação, os políticos que representavam o governo local procuravam exercer influência sobre o processo orçamentário. Após a aprovação, faziam lobby para forçar a execução dos desembolsos. O "pagamento" feito pelas empresas aos políticos dava-se sob a forma de uma "bonificação de incentivo", em um valor entre $5 \%$ e $20 \%$ do preço total do investimento. Aparentemente, todos os estágios incluíam o suborno de funcionários públicos diretamente envolvidos com o processo orçamentário do Congresso e os políticos que faziam o papel de "administradores".

O segundo esquema, das transferências sociais, favorecia diretamente os parlamentares envolvidos no orçamento. Era um exemplo claro de corrupção clientelista. Os políticos envolvidos procuravam criar entidades de assis- tência social e registrá-las perante o Conselho Nacional de Assistência Social. Essas instituições - erroneamente entituladas ONGs (organizações não governamentais) - podem receber recursos do orçamento para a suposta prestação de serviços sociais. A maioria era criada e administrada pelos próprios políticos ou por suas famílias. Muitos deles usavam as instituições como beneficiárias de cessões de suas propriedades - uma maneira de alegar a ausência de bens pessoais. Fraudes primárias, como a emissão de recibos ilegais e o emprego de funcionários fantasmas, eram usadas para privatizar recursos públicos. O esquema envolvia apenas os deputados da Comissão do Orçamento, ao contrário do primeiro, que era mais abrangente.

Então, o que se pode deduzir da análise desses casos? Primeiro, que não havia vigilância adequada sobre o processo orçamentário. Inexistiam tanto o controle judiciário, por parte do Tribunal de Contas da União, quanto o interno, por parte do Congresso. O segundo fato, deplo-

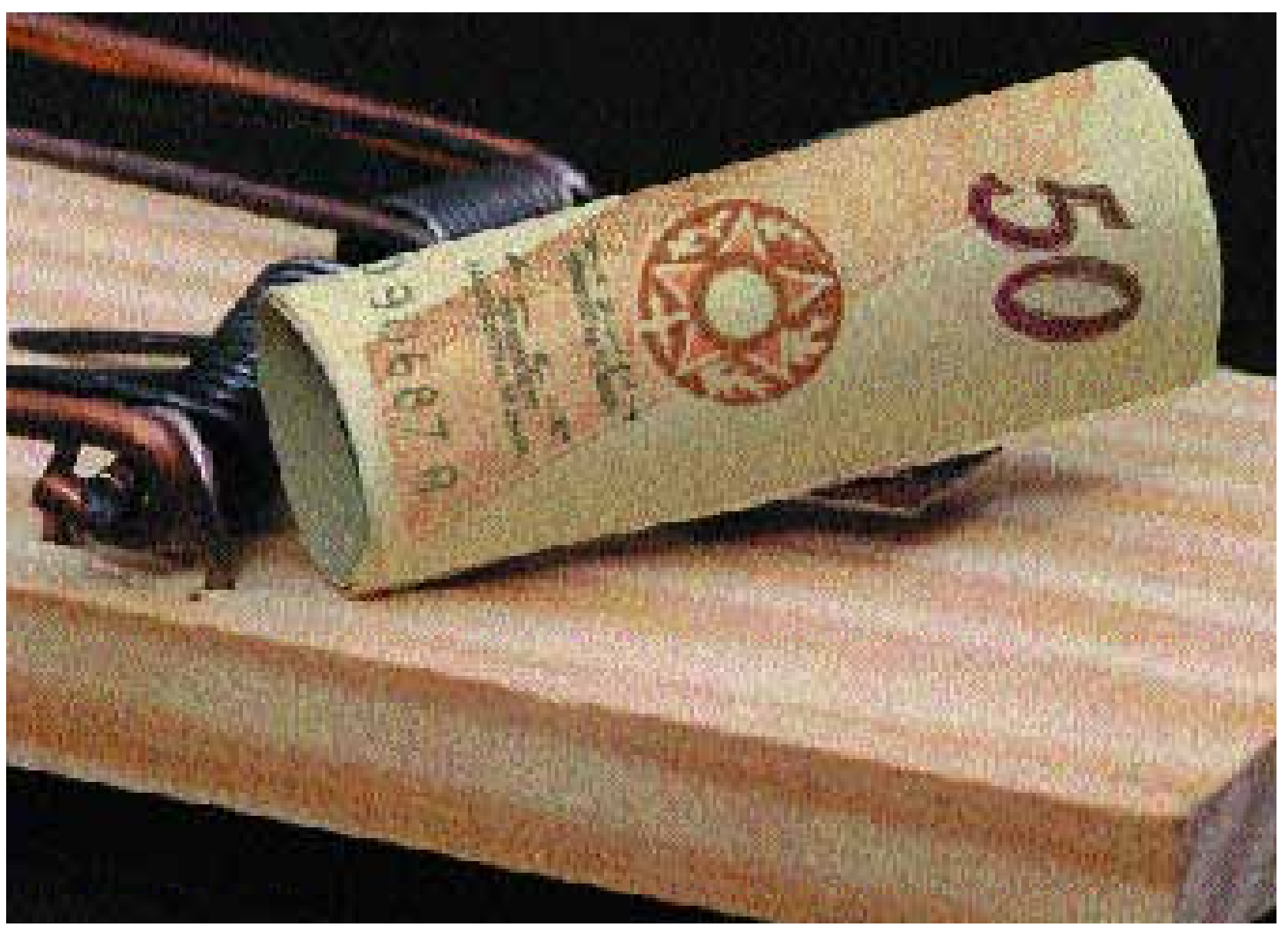


rável, é que os "sete anões" eram sabidamente corruptos anos antes do escândalo. Isso revela, infelizmente, fortes indícios de que o esquema era de conhecimento praticamente geral do Congresso, e de que muitos legisladores aproveitavam-se dele para obter benefícios indiretos.

Como afirmamos, o estabelecimento da democracia e de maiores poderes ao Congresso não trouxe qualquer aperfeiçoamento do sistema de controle. Esse fato, associado a um Congresso clientelista, criou as condições para a manutenção da corrupção. A corrupção orçamentária é caracterizada, principalmente, por questões estruturais ligadas à natureza interna do fenômeno. Essas questões não estão especificamente relacionadas ao processo orçamentário. Aparentemente, os brasileiros ignoram ou toleram a corrupção, ou simplesmente a aceitam como traço cultural do homo brasiliensis. Por outro lado, o Brasil sofre de um subdesenvolvimento institucional.

\section{O papel exercido pelas instituições. A} corrupção é um fenômeno universal que permeia a vida pública e privada de países desenvolvidos e em desenvolvimento há tempos. Mas em muitos deles, pelo menos em parte, a corrupção foi controlada por meio de esforços da lei, da imprensa e do poder público.

$\mathrm{Na}$ Inglaterra e na França, por exemplo, a corrupção já foi endêmica e crônica, mas a evolução institucional, especialmente no caso da Inglaterra, restringiu e controlou os atos de políticos e funcionários públicos. Tal progresso foi resultado da modernização do funcionalismo público e da constituição do Estado democrático moderno. Nesses casos, instituições como um governo democrático e a opinião pública desempenham uma importante função de controle.

Nessas sociedades, passou-se do clientelismo e do patrimonialismo para a obediência por meio da administração da propriedade pública - considerada a existência de um sistema de delito e punição. O Estado democrático moderno trouxe, a uma burocracia profissional, uma base política desenvolvida, composta de partidos organizados e eleitores informados, e um poder judiciário eficiente. $\mathrm{O}$ estudo de exemplos históricos demonstra que a evolução das regras e dos valores que geraram essas instituições estabelece um ambiente de ilegalidade e ilegitimidade para a corrupção.
A luta contra a corrupção exige um engajamento cívico profundo da população e da Justiça. O processo de impeachment do ex-presidente Collor deixou claro o fato de que é possível o envolvimento contra a corrupção na sociedade brasileira. Mas não podemos nos deixar levar por ilusões: o impeachment surgiu principalmente do cenário políticoeconômico. O mau desempenho da economia brasileira, a violência do confisco de bens e poupança no contexto do programa de estabilização e o comportamento pouco profissional da equipe econômica criaram o ambiente ideal para um processo contra o então presidente.

\section{A corrupção é, em si, um fato econômico. É tanto uma atividade econômica quanto um crime e implica em custos para a sociedade e riscos para as empresas.}

A economia política da corrupção. Em longo prazo, há custos que estão associados à corrupção. Em primeiro lugar, as atividades corruptas reduzem a eficiência das organizações tanto privadas quanto públicas. E, em segundo, elas podem representar custos em termos de crescimento econômico, por significar atividades improdutivas, meras transferências ilegais de renda.

A corrupção depende da evolução institucional e deve ser estudada como fenômeno econômico, pois o método econômico pode ser aplicado a pesquisas sobre suborno e corrupção. Além disso, a corrupção é, em si, um fato econômico. É tanto uma atividade econômica quanto um crime e implica em custos para a sociedade e riscos para as empresas.

Tais informações constituem argumentos suficientes para dar sustentação à inclusão definitiva da corrupção na agenda de pesquisa econômica. Ainda assim, embora este seja um avanço real, a maior parte dos acadêmicos da economia infelizmente não a considera como um problema econômico relevante. 